\title{
RUTHENIUM (III) - CATALYZED OXIDATIVE CLEAVAGE OF PHENYLPROPANOLAMINE HYDROCHLORIDE WITH SODIUM N-CHOROBEZENESULFONAMIDE IN ACID MEDIUM: A KINETIC AND MECHANISTIC STUDY
}

\author{
KIKKERI N. MOHANA*, NINGEGOWDA PRASAD
}

Department of Studies in Chemistry, University of Mysore Manasagangotri Mysore-570 006, India

(Received: January 2, 2008 - Accepted: July 19, 2008)

\begin{abstract}
Phenylpropanolamine hydrochloride (2-amino-1-phenylpropanol hydrochloride) is a sympathomimetric drug used for nasal congestion associated with the common cold, allergies, high fever, or other respiratory illness. The kinetics of oxidation of phenylpropanolamine hydrochloride (PPA) with sodium $N$ chlorobenzenesulfonamide or chloramine-B (CAB) catalyzed by $\mathrm{Ru}$ (III) in hydrochloric acid medium has been studied at $308 \mathrm{~K}$. The oxidation reaction follows the rate law, $-\mathrm{d}[\mathrm{CAB}] / \mathrm{dt}=\mathrm{k}[\mathrm{CAB}]\left[\mathrm{H}^{+}\right]^{\mathrm{x}}[\mathrm{PPA}]^{\mathrm{y}}[\mathrm{Ru}(\mathrm{III})]^{\mathrm{z}}$, where $\mathrm{x}, \mathrm{y}$ and $\mathrm{z}$ are less than unity. Addition of chloride ions, perchlorate ions and the reduction product of $\mathrm{CAB}$, benzenesulfonamide (BSA), have no significant effect on the rate. Decrease of dielectric permittivity of the medium by increasing the $\mathrm{CH}_{3} \mathrm{CN}$ content increased the rate. The reaction was studied at different temperatures and the activation parameters have been computed from the Arrhenius plot. The stoichiometery of the reaction was found to be 1:1 and the main oxidation products of PPA were found to be benzaldehyde and acetaldehyde. The rate constant decreases in $\mathrm{D}_{2} \mathrm{O}$ medium and the normal isotope effect, $\mathrm{k}^{\prime}\left(\mathrm{H}_{2} \mathrm{O}\right) / \mathrm{k}^{\prime}\left(\mathrm{D}_{2} \mathrm{O}\right)$ is 2.39. Proton inventory studies have been made in $\mathrm{H}_{2} \mathrm{O}-\mathrm{D}_{2} \mathrm{O}$ mixtures. Formation and decomposition constant of CAB-PPA complexes in the reaction scheme have been evaluated. The conjugate acid $\mathrm{C}_{6} \mathrm{H}_{5} \mathrm{SO}_{2} \mathrm{NHCl}^{2}$ has been assumed to be the reactive species. The observed results have been explained by plausible mechanisms and relative rate law has been deduced.
\end{abstract}

Keywords: Phenylpropanolamine hydrochloride, chloramine-B, oxidation Kinetics, Ru(III)-catalysis, acid medium.

\section{INTRODUCTION}

Considerable attention has centered on the chemistry of $N$-metallo- $N$ arylhalosulfonamides, generally known as organic haloamines, because of their versatility and their behavior both as bases and nucleophiles. The prominent member of this group is chloramine-T (CAT) and the mechanistic aspects of many of its reactions have been documented ${ }^{1-3}$. The benzene analogue chloramine- $\mathrm{B}(\mathrm{CAB})$ is gaining importance as a mild oxidant $t^{4-6}$. Conductometric study of the interaction of $\mathrm{CAB}$ with some metal ion solutions ${ }^{7}$ and photolysis of aqueous solution of $\mathrm{CAB}$ has been reported ${ }^{8}$.

Phenylpropanolamine hydrochloride (PPA) is a sympathomimetic drug, differing from amphetamine by only a hydroxyl group on the $\beta$-carbon atom. PPA is used for nasal congestion associated with the common cold, allergies, high fever or other respiratory illness. It has been used as a non prescription diet-aid for weight loss9. Survey of literature reveals that, there was no information available on the oxidation kinetics of phenylpropanolamine with any oxidant. There was a need for understanding the oxidation mechanism of this drug, so that the study could through some light on the fate of the drug in the biological system.

In view of these facts, there is a considerable scope in the study of redox behavior of CAB towards PPA and understand its redox chemistry in solutions. In the light of the available information and our continued interest on mechanistic studies on haloaminometric reactions in general and bioactive compounds in particular, the present investigation was undertaken. The reaction of PPA with $\mathrm{CAB}$ in $\mathrm{HCl}$ medium without a catalyst was found to be sluggish, but the reaction was found to be facile in the presence of $\mathrm{Ru}(\mathrm{III})$ catalyst. The present paper reports the kinetics of Ru(III)-catalyzed oxidation of PPA with $\mathrm{CAB}$ in $\mathrm{HCl}$ medium at $308 \mathrm{~K}$ in order to (i) elucidate the reaction mechanism of metabolic conversions of the substrate in biological syste, (ii) Put forward appropriate rate law, (iii) Ascertain the reactive species and (iv) identify the products of reaction.

\section{EXPERIMENTAL}

\section{Materials}

Chloramine-B was prepared and purified by the method reported earlier ${ }^{10}$. An aqueous solution of the compound was standardized iodometrically and preserved in brown bottles to prevent its photochemical deterioration. Pharmaceutical grade PPA (supplied by Cipla India Ltd., Mumbai, India) was used as received. Aqueous solution of the compound was prepared freshly each time. All other chemicals used were of analytical grade. Ionic strength of the reaction mixture was kept constant with a concentrated solution of $\mathrm{NaClO}_{4}$
(Merck). Doubly distilled water was used for the preparation of aqueous solutions.

\section{Kinetic measurements}

The kinetic runs were performed under pseudo-first-order conditions. Required amounts of solutions of the $\mathrm{PPA}, \mathrm{HCl}, \mathrm{NaClO}_{4}$, were charged into a stoppered Pyrex glass tubes whose outer surfaces were coated black to eliminate photochemical effects. In each case, a required amount of water was added to maintain a constant total volume. The tube was thermostated in water both set at a given temperature $(308 \pm 0.1 \mathrm{~K})$. To this solution, a measured amount of pre-equilibrated $\mathrm{CAB}$ solution was added to give a known concentration. The progress of the reaction was monitored iodometrically for two half-lives by withdrawing aliquots of the reaction mixture at regular time intervals. The rate constants, $\mathrm{k}^{\prime}$ were reproducible within $\pm 3 \%$. Regression analysis of the experimental data to obtain regression coefficient, $r$, was made using MS-excel program.

\section{RESULTS}

\section{Stiochiometry and product analysis}

Reaction mixtures containing different compositions of PPA and $\mathrm{CAB}$ were equilibrated in presence of $\mathrm{HCl}\left(0.1 \mathrm{~mol} \mathrm{dm}^{-3}\right)$ and $\mathrm{RuCl}_{3}\left(1 \times 10^{-4} \mathrm{~mol}\right.$ $\mathrm{dm}^{-3}$ ) for $48 \mathrm{hrs}$ at $308 \mathrm{~K}$. Determination of unreacted oxidant in the reaction mixture showed that one mole of PPA was consumed per mole of oxidant, confirming the following stoichiometry:

$$
\mathrm{C}_{9} \mathrm{H}_{13} \mathrm{NO}+\mathrm{RNClNa}+\mathrm{H}_{2} \mathrm{O} \longrightarrow \mathrm{C}_{7} \mathrm{H}_{6} \mathrm{O}+\mathrm{C}_{2} \mathrm{H}_{4} \mathrm{O}+\mathrm{RNH}_{2}+\mathrm{NaCl}+\mathrm{NH}_{3}
$$

$$
\text { where } \mathrm{R}=\mathrm{C}_{6} \mathrm{H}_{5} \mathrm{SO}_{2} \text {. }
$$

The products in the reaction mixture were extracted several times with diethyl ether. The combined ether extract was evaporated and subjected to column chromatography on silica gel using gradient elusion (chloroform). The reduction product of $\mathrm{CAB}$, benzenesulfonamide (BSA) was detected by paper chromatography ${ }^{11}$. Benzyl alcohol saturated with water was used as the solvent with $0.5 \%$ vanillin in $1 \% \mathrm{HCl}$ solution in ethanol as spray reagent $\left(\mathrm{R}_{\mathrm{f}}=0.88\right)$. The oxidation products of PPA were found to be benzaldehyde, acetaldehyde and ammonia. Formation of ammonia was quantitatively estimated by microKjeldahl procedure. Benzaldehyde and acetaldehyde were detected by spot tests $^{12}$. Benzaldehyde was identified by preparing 2, 4-DNP derivative. Further the products were confirmed by IR absorption bands. BSA: $3347,3258 \mathrm{~cm}$ ${ }^{1}\left(\mathrm{~N}-\mathrm{H}\right.$ stretch); $1334 \mathrm{~cm}^{-1}\left(\mathrm{SO}_{2}\right.$ asymm. stretch $) ; 1660 \mathrm{~cm}^{-1}\left(\mathrm{SO}_{2}\right.$ sym. stretch) 
and $994 \mathrm{~cm}^{-1}$ (S-N stretch). Benzaldehyde: $1704 \mathrm{~cm}^{-1}$ (C=O stretch) and 2848 $\mathrm{cm}^{-1}$ (aldehydic C-H stretch). IR spectra were recorded on JASCO FT-IR spectrometer using $\mathrm{KBr}$ pellets.

\section{Effect of varying reactant concentrations on the rate}

The reaction was performed in presence of $\mathrm{Ru}(\mathrm{III})$-catalyst and $\mathrm{HCl}$ under pseudo-first-order conditions ([PPA $]>>[C A B])$. Plots of $\log [\mathrm{CAB}]$ versus time were linear $(r>0.996)$. The linearity of these plots together with the constancy of the slope for various $[\mathrm{CAB}]_{0}$, indicates a first-order dependence of the reaction rate on $[\mathrm{CAB}]$. The pseudo-first-order rate constants, $\mathrm{k}^{\prime}$ obtained at $308 \mathrm{~K}$ are listed in Table 1 . The reaction rate increased with increase in [PPA] (Table 1), and a plot of log k' versus $\log [\mathrm{PPA}]$ was linear $(\mathrm{r}=0.988)$ with a slope of 0.4 indicating a fractional-order dependence on $[\mathrm{PPA}]_{0}$.

\section{Effect of varying concentration of $\mathrm{HCl}$ on the rate}

At constant $[\mathrm{CAB}],[\mathrm{PPA}],[\mathrm{Ru}(\mathrm{III})]$, ionic strength and temperature, the rate of reaction increased with increase in $[\mathrm{HCl}]$ (Table 1). A plot of log k' versus $\log [\mathrm{HCl}]$ was linear $(\mathrm{r}=0.995$; Fig. 1$)$, with a slope of 0.74 indicating a fractional-order dependence on $[\mathrm{HCl}]$.

Table 1. Effect of varying concentrations of reactants and acid on the reaction rate constant at $308 \mathrm{~K}\left[\mathrm{RuCl}_{3}\right]=1 \times 10^{-4} \mathrm{~mol} \mathrm{dm}^{-3}$ and $\mu=0.2 \mathrm{~mol}$ $\mathrm{dm}^{-3}$

\begin{tabular}{|c|c|c|c|}
\hline $\begin{array}{r}10^{4}[\mathrm{CAB}] \\
\left(\mathrm{mol} \mathrm{dm}^{-3}\right)\end{array}$ & $\begin{array}{c}10^{3}[\mathrm{PPA}] \\
\left(\mathrm{mol} \mathrm{dm}^{-3}\right)\end{array}$ & $\begin{array}{c}10^{2}[\mathrm{HCl}] \\
\left(\mathrm{mol} \mathrm{dm}^{-3}\right)\end{array}$ & $\begin{array}{c}10^{4} k^{\prime} \\
\left(\mathrm{s}^{-1}\right)\end{array}$ \\
\hline 3.0 & 8.0 & 10.0 & 4.39 \\
\hline 5.0 & 8.0 & 10.0 & 4.37 \\
\hline 7.0 & 8.0 & 10.0 & 4.35 \\
\hline 9.0 & 8.0 & 10.0 & 4.42 \\
\hline 11.0 & 8.0 & 10.0 & 4.40 \\
\hline 5.0 & 4.0 & 10.0 & 3.55 \\
\hline 5.0 & 6.0 & 10.0 & 4.02 \\
\hline 5.0 & 10.0 & 10.0 & 4.70 \\
\hline 5.0 & 12.0 & 10.0 & 5.31 \\
\hline 5.0 & 8.0 & 8.0 & 3.76 \\
\hline 5.0 & 8.0 & 12.0 & 5.08 \\
\hline 5.0 & 8.0 & 14.0 & 5.71 \\
\hline 5.0 & 8.0 & 16.0 & 6.21 \\
\hline$* 5.0$ & 8.0 & 10.0 & 4.35 \\
\hline$* * 5.0$ & 8.0 & 10.0 & 4.41 \\
\hline & & & \\
\hline
\end{tabular}

* In presence of benzensulfonamide.

** At ionic strength $0.5 \mathrm{~mol} \mathrm{dm}^{-3}$.

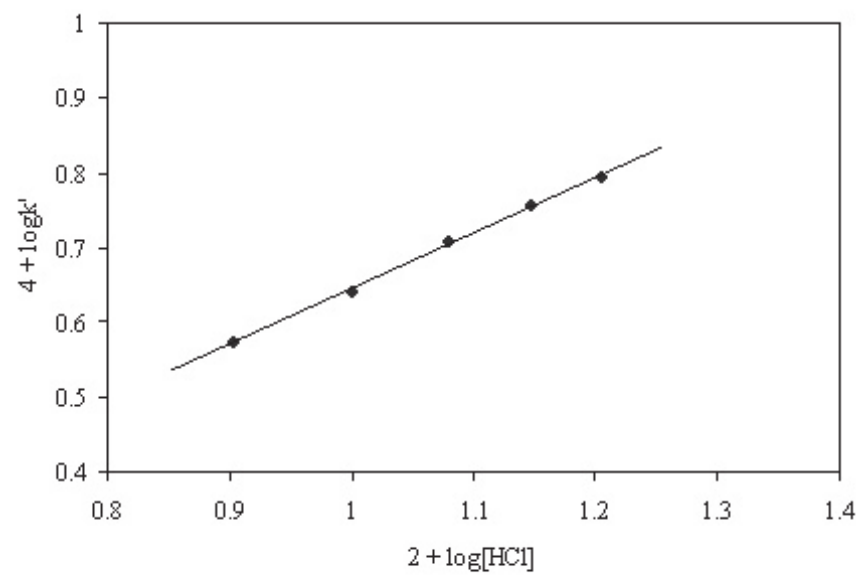

Fig. 1

Fig. 1: Plot of $4+\log k^{\prime}$ vs. $2+\log [\mathrm{HCl}]$.

\section{Effect of added $\left[\mathrm{Cl}^{-}\right]$on the rate}

The addition of $\left[\mathrm{Cl}^{-}\right]$in the form of $\mathrm{NaCl}$, keeping $\left[\mathrm{H}^{+}\right]$constant did not affect the rate of reaction (Table 2). Hence, the dependence of the rate on [HCl] reflected the effect of $\left[\mathrm{H}^{+}\right]$only on the reaction.

\section{Effect of varying $[\mathrm{Ru}(\mathrm{III})]$ on the rate}

The reaction rate increased with increase in $[\mathrm{Ru}(\mathrm{III})]$ (Table 2), and a plot of $\log \mathrm{k}$ ' versus $\log [\mathrm{Ru}(\mathrm{III})]$ was linear (Fig.2; $\mathrm{r}=0.999$ ) with a slope of 0.24 indicating a fractional-order dependence on $[\mathrm{Ru}(\mathrm{III})]$.

Table 2. Effect of varying $\mathrm{Cl}^{-}$and $\mathrm{RuCl}_{3}$ concentrations on the reaction rate constant $[\mathrm{CAB}]_{0}=5 \times 10^{-4} \mathrm{~mol} \mathrm{dm}^{-3},[\mathrm{PPA}]=8 \times 10^{-3} \mathrm{~mol} \mathrm{dm}^{-3},\left[\mathrm{H}^{+}\right]=10$ $\times 10^{-2} \mathrm{~mol} \mathrm{dm}^{-3} \mu=0.2 \mathrm{~mol} \mathrm{dm}^{-3}$ and $\mathrm{T}=308 \mathrm{~K}$

\begin{tabular}{|c|c|c|}
\hline $\begin{array}{c}10^{2}\left[\mathrm{Cl}^{-}\right] \\
\left(\mathrm{mol} \mathrm{dm}^{-3}\right)\end{array}$ & $\begin{array}{c}10^{4}\left[\mathrm{RuCl}_{3}\right] \\
\left(\mathrm{mol} \mathrm{dm}^{-3}\right)\end{array}$ & $\begin{array}{c}10^{4} k^{\prime} \\
\left(\mathrm{s}^{-1}\right)\end{array}$ \\
\hline 12.0 & 1.0 & 4.41 \\
\hline 14.0 & 1.0 & 4.38 \\
\hline 17.0 & 1.0 & 4.35 \\
\hline 20.0 & 1.0 & 4.33 \\
\hline 25.0 & 1.0 & 4.36 \\
\hline 10.0 & 0.5 & 3.71 \\
\hline 10.0 & 0.8 & 4.16 \\
\hline 10.0 & 1.0 & 4.37 \\
\hline 10.0 & 2.0 & 5.25 \\
\hline 10.0 & 3.0 & 5.85 \\
\hline
\end{tabular}

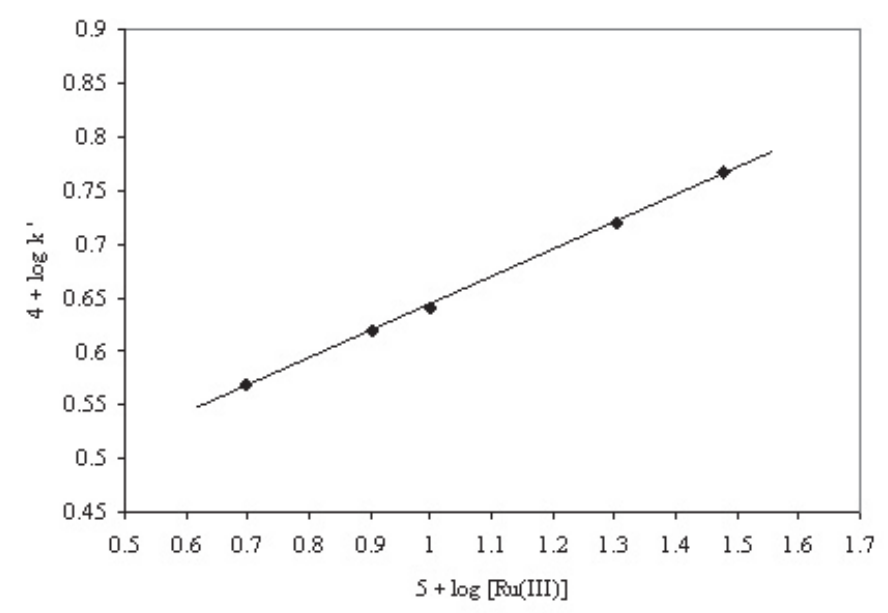

Fig 2

Fig. 2: Plot of 4+log k’ vs. $5+\log [\mathrm{Ru}(\mathrm{III})]$.

6. Effect of varying benzenesulfonamide and ionic strength on the rate

Addition of the reduced product, benzenesulfonamide $\left(2 \times 10^{-4}\right.$ to $8 \times 10^{-4}$ mol dm ${ }^{-3}$ ) and variation of ionic strength of the medium using $\mathrm{NaClO}_{4}$ to the reaction mixture had no significant effect on the rate.

\section{Effect of relative permittivity of the medium on the reaction rate}

The effect of relative permittivity (D) of the medium on the rate has been studied by using the $\mathrm{CH}_{3} \mathrm{CN}-\mathrm{H}_{2} \mathrm{O}$ content in the reaction mixture with all other conditions kept constant. The values of relative permittivity were computed from the values of the pure liquids ${ }^{13}$. The rate constant, $k^{\prime}$ increases with decreasing relative permittivity of the medium (Table 3). Plot of $\log k^{\prime}$ versus 1/D gave a straight line $(\mathrm{r}=0.998)$ with a positive slope. Blank experiments 
performed showed that $\mathrm{CAB}$ did not oxidize $\mathrm{CH}_{3} \mathrm{CN}$ under the experimental conditions employed.

Table 3. Effect of solvent composition and temperature on the reaction rate constant $[\mathrm{CAB}]_{0}=5 \times 10^{-4} \mathrm{~mol} \mathrm{dm}^{-3},[\mathrm{PPA}]_{0}=8 \times 10^{-3} \mathrm{~mol} \mathrm{dm}^{-3},[\mathrm{HCl}]=$ $10 \times 10^{-2} \mathrm{~mol} \mathrm{dm}^{-3}\left[\mathrm{RuCl}_{3}\right]=1 \times 10^{-4} \mathrm{~mol} \mathrm{dm}^{-3}$ and $\mu=0.2 \mathrm{~mol} \mathrm{dm}^{-3}$

\begin{tabular}{|c|c|c|}
\hline Temperature $(\mathrm{K})$ & $\mathrm{CH}_{3} \mathrm{CN}(\%, \mathrm{v} / \mathrm{v})$ & $10^{4} k^{\prime}\left(\mathrm{s}^{-1}\right)$ \\
\hline 308 & 0 & 4.37 \\
\hline 308 & 5 & 4.46 \\
\hline 308 & 10 & 4.76 \\
\hline 308 & 15 & 4.95 \\
\hline 308 & 20 & 5.15 \\
\hline 303.4 & - & 2.57 \\
\hline 308 & - & 4.37 \\
\hline 313 & - & 8.02 \\
\hline 318 & - & 13.32 \\
\hline 321 & - & 18.47 \\
\hline
\end{tabular}

\section{Effect of solvent isotope on the rate}

As the rate is dependent on $\left[\mathrm{H}^{+}\right]$, solvent isotope study in $\mathrm{D}_{2} \mathrm{O}$ medium was made. The value of $k^{\prime}\left(\mathrm{H}_{2} \mathrm{O}\right)$ is $4.37 \times 10^{-4} \mathrm{~s}^{-1}$ and that of $k^{\prime}\left(\mathrm{D}_{2} \mathrm{O}\right)$ is $1.83 \times 10^{-4}$ $\mathrm{s}^{-1}$ leading to solvent isotope effect, $k^{\prime}\left(\mathrm{H}_{2} \mathrm{O}\right) / k^{\prime}\left(\mathrm{D}_{2} \mathrm{O}\right)=2.39$. Proton inventory studies were made in $\mathrm{H}_{2} \mathrm{O}-\mathrm{D}_{2} \mathrm{O}$ mixtures, and the results are shown in Table 4. The corresponding proton inventory plot for the rate constant $\mathrm{k}$ ' in a solvent mixture containing deuterium atom fraction (n) is given in Fig. 3.

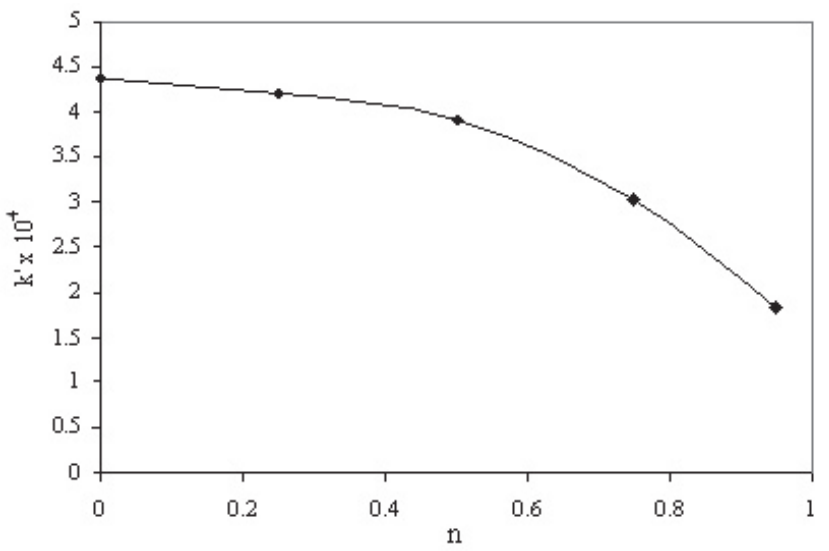

Fig 3

Fig. 3: Plot of k’ vs. n.

Table 4. Proton inventory studies for the oxidation of PPA in $\mathrm{H}_{2} \mathrm{O}-\mathrm{D}_{2} \mathrm{O}$ mixture at $308 \mathrm{~K}[\mathrm{CAB}]_{0}=5 \times 10^{-4} \mathrm{~mol} \mathrm{dm}^{-3},[\mathrm{PPA}]_{0}=8 \times 10^{-3} \mathrm{~mol} \mathrm{dm}^{-3}$, $[\mathrm{HCl}]=10 \times 10^{-2} \mathrm{~mol} \mathrm{dm}^{-3}\left[\mathrm{RuCl}_{3}\right]=1 \times 10^{-4} \mathrm{~mol} \mathrm{dm}^{-3}$ and $\mu=0.2 \mathrm{~mol} \mathrm{dm}^{-3}$

\begin{tabular}{|c|c|}
\hline $\begin{array}{c}\text { Atom fraction of } \mathrm{D}_{2} \mathrm{O} \\
(\mathrm{n})\end{array}$ & $10^{4} k^{\prime}\left(\mathrm{s}^{-1}\right)$ \\
\hline 0.00 & 4.38 \\
\hline 0.25 & 4.20 \\
\hline 0.50 & 3.92 \\
\hline 0.75 & 3.30 \\
\hline 0.85 & 2.51 \\
\hline
\end{tabular}

\section{Effect of temperature on the rate}

The reaction was studied at different temperatures (303.4-321 K) keeping other experimental conditions constant (Table 3). From the Arrhenius plot of $\log k^{\prime}$ versus $1 / \mathrm{T}(\mathrm{r}=0.998)$, activation energy and other thermodynamic parameters were found to be $E_{\mathrm{a}}=86.29 \mathrm{~kJ} \mathrm{~mol}^{-1}, \Delta H^{\neq}=83.70 \mathrm{~kJ} \mathrm{~mol}^{-1} ; \Delta G^{\ddagger}=$ $71.99 \mathrm{~kJ} \mathrm{~mol}^{-1}$ and $\Delta S^{\neq}=-37.46 \mathrm{JK}^{-1} \mathrm{~mol}^{-1}$.

\section{Test for free radicals}

The addition of the reaction mixture to an aqueous acrylamide monomer solution did not initiate polymerization indicating the absence of in situ formation of free radical species in the reaction sequence.

\section{DISCUSSION AND MECHANISM}

Bishop and Jennings ${ }^{14}$, Morris et $a l^{15}$ and Higuchi and co-workers ${ }^{16}$ have shown the existence of similar equilibria in acid and alkaline solutions of metal salts of $\mathrm{N}$-haloarenesulfonamides. Chloramine-B an analogue to chloramine-T behaves as a strong electrolyte in aqueous solutions and furnishes different types of reactive species in acidic solutions. To confirm this hypothesis, conductometric and $\mathrm{pH}$-titrations between aqueous solutions of $\mathrm{CAB}$ and $\mathrm{HCl}$ were performed. The conductometric behavior of $\mathrm{CAB}$ is identical with that of $\mathrm{CAT}^{17,18}$, while the $\mathrm{pH}$ titration curves observed are similar to those noted by Morris et $\mathrm{al}^{15}$. The possible equilibria in acidified CAB solutions are,

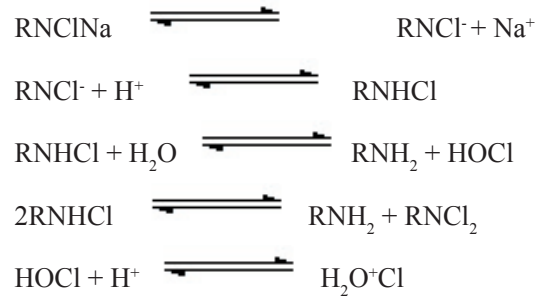

where $\mathrm{R}$ is $\mathrm{C}_{6} \mathrm{H}_{5} \mathrm{SO}_{2}$.

The possible oxidizing species in acidified $\mathrm{CAB}$ solutions are dichloramine$\mathrm{B}\left(\mathrm{RNCl}_{2}\right)$, the conjugate acid $(\mathrm{RNHCl}), \mathrm{HOCl}$ and $\mathrm{H}_{2} \mathrm{O}^{+} \mathrm{Cl}$. If $\mathrm{RNCl}_{2}$ were to be the reactive species, then the rate law predicts the second-order dependence on $[\mathrm{CAB}]_{0}$, and negative effect of BSA according to Eq. (5), which is not in agreement with the experimental observation. If $\mathrm{HOCl}$ acts as a reactive oxidant species a first-order retardation of rate on added BSA $\left(\mathrm{RNH}_{2}\right)$ was expected. However, there was no such effect is seen. Hardy and Johnston ${ }^{19}$, who studied the $\mathrm{pH}$ dependent relative concentrations of the species present in acidified bromamine-B solutions of comparable molarities, have shown that $\mathrm{RNHBr}$ is the likely oxidizing species in acid medium. Narayanan and $\mathrm{Rao}^{20}$ and Subhashini et al $^{21}$ have reported that monohaloamines can be further protonated at $\mathrm{pH} 2$ as shown in the following equations (7) and (8) for monochloramine-T $\left(\mathrm{CH}_{3} \mathrm{C}_{6} \mathrm{H}_{4} \mathrm{SO}_{2} \mathrm{NHCl}\right)$ and monochloramine- $\mathrm{B}\left(\mathrm{C}_{6} \mathrm{H}_{5} \mathrm{SO}_{2} \mathrm{NHCl}\right)$, respectively.

$$
\begin{aligned}
& \mathrm{CH}_{3} \mathrm{C}_{6} \mathrm{H}_{4} \mathrm{SO}_{2} \mathrm{NHCl}+\mathrm{H}^{+} \rightleftharpoons \mathrm{CH}_{3} \mathrm{C}_{6} \mathrm{H}_{4} \mathrm{SO}_{2} \mathrm{~N}^{+} \mathrm{H}_{2} \mathrm{Cl} \\
& \mathrm{C}_{6} \mathrm{H}_{5} \mathrm{SO}_{2} \mathrm{NHCl}+\mathrm{H}^{+} \rightleftharpoons \mathrm{C}_{6} \mathrm{H}_{5} \mathrm{SO}_{2} \mathrm{~N}^{+} \mathrm{H}_{2} \mathrm{Cl}
\end{aligned}
$$

The second protonation constants for chloramine- $\mathrm{T}$ and chloramine-B are $102 \mathrm{M}^{-1}$ and $61 \pm 5 \mathrm{M}^{-1}$ respectively at $25^{\circ} \mathrm{C}$.

Cady and Connick ${ }^{22}$ and Connick and $\mathrm{Fine}^{23}$ based on the ion exchange properties and UV-spectral studies have shown that octahedral complexes such as $\left[\mathrm{RuCl}_{5}\left(\mathrm{H}_{2} \mathrm{O}\right)\right]^{2-},\left[\mathrm{RuCl}_{4}\left(\mathrm{H}_{2} \mathrm{O}\right)_{2}\right]^{-},\left[\mathrm{RuCl}_{3}\left(\mathrm{H}_{2} \mathrm{O}\right)_{3}\right],\left[\mathrm{RuCl}_{2}\left(\mathrm{H}_{2} \mathrm{O}\right)_{4}\right]^{+}$and $\left[\mathrm{RuCl}\left(\mathrm{H}_{2} \mathrm{O}\right)_{5}\right]^{2+}$ may not exist in aqueous solution of $\mathrm{RuCl}_{3}$. However other studies $^{24-26}$ have shown that the following ligand substitution equilibrium in acidic solution,

$$
\begin{gathered}
\mathrm{RuCl}_{3} \cdot \mathrm{xH}_{2} \mathrm{O}+\mathrm{HCl} \longrightarrow\left[\mathrm{RuCl}_{6}\right]^{3-}+\mathrm{x} \mathrm{H}_{2} \mathrm{O} \\
{\left[\mathrm{RuCl}_{6}\right]^{3-}+\mathrm{H}_{2} \mathrm{O} \longrightarrow\left[\mathrm{RuCl}_{5}\left(\mathrm{H}_{2} \mathrm{O}\right)\right]^{2-}+\mathrm{Cl}^{-}}
\end{gathered}
$$

Singh et al ${ }^{27,28}$ have used the above equilibrium in $\mathrm{Ru}(\mathrm{III})$-catalyzed 
oxidation of primary alcohols by bromamine-T and ethylene glycols by $\mathrm{N}$ bromoacetamide in $\mathrm{HClO}_{4}$ medium. In the present study however, the absence of chloride ion effect on the rate indicates that, equilibrium (9) does not play a role in the reaction and hence the complex ion, $\left[\left(\mathrm{RuCl}_{5}\left(\mathrm{H}_{2} \mathrm{O}\right)\right]^{2-}\right.$ is assumed to be the reactive catalyzing species. Similar results were observed in the $\mathrm{Ru}(\mathrm{III})$ catalyzed oxidations of chloroacetic acid ${ }^{29}$, ethanols ${ }^{30}$ by bromamine- $\mathrm{T}$ and $\mathrm{N}$-heterocycles by chloramine- $\mathrm{T}^{31}$.

Ultraviolet spectral measurements showed that a sharp absorption band was noticed at $214 \mathrm{~nm}$ for $\mathrm{RuCl}_{3}, 226.5 \mathrm{~nm}$ for $\mathrm{CAB}$ and around $216 \mathrm{~nm}$ for PPA in presence of $0.1 \mathrm{~mol} \mathrm{dm}^{-3} \mathrm{HCl}$. A mixture of $\mathrm{CAB}$ and $\mathrm{RuCl}_{3}$ solutions in the presence of $\mathrm{HCl}$ showed an absorption band at $268 \mathrm{~nm}$, while for a mixture of PPA and $\mathrm{Ru}(\mathrm{III})$ solutions an absorption band was noticed at 212 $\mathrm{nm}$. The spectral evidence showed that complex formation takes place only between $\mathrm{Ru}(\mathrm{III})$ and $\mathrm{CAB}$.

Based on the preceding discussion, a detailed mechanistic interpretation (Scheme 1) for the $\mathrm{Ru}(\mathrm{III})$-catalyzed CAB-PPA reaction in acid medium has been proposed to substantiate the observed kinetics.

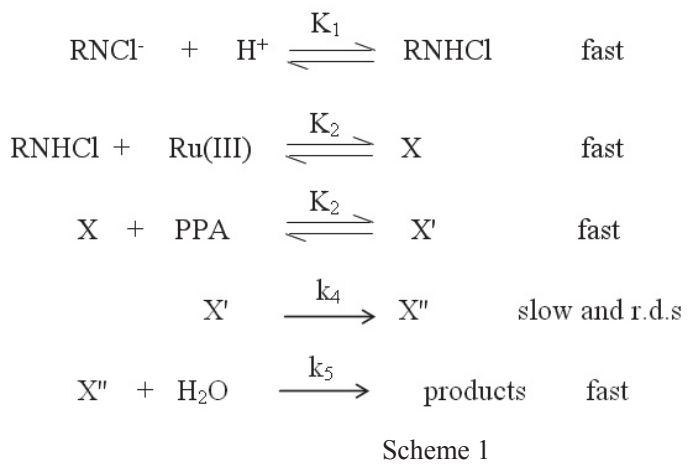

Step (iv) of Scheme 1 determines over all rate law,

rate $=-\mathrm{d}[\mathrm{CAB}] / \mathrm{dt}=\mathrm{k}_{4}\left[\mathrm{X}^{\prime}\right]$

If $[\mathrm{CAB}]_{\mathrm{t}}$ represents total $[\mathrm{CAB}]$ in solution, then

$[\mathrm{CAB}]_{\mathrm{t}}=[\mathrm{RNCl}-]+[\mathrm{RNHCl}]+[\mathrm{X}]+\left[\mathrm{X}^{\prime}\right]$

From, steps (i), (ii) and (iii) of Scheme 1

$$
\begin{aligned}
{\left[\mathrm{RNCl}^{-}\right] } & =\frac{[\mathrm{RNHCl}]}{\mathrm{K}_{1}\left[\mathrm{H}^{+}\right]} \\
{[\mathrm{RNHCl}] } & =\frac{[\mathrm{X}]}{\mathrm{K}_{1}[\mathrm{Ru}(\mathrm{III})]} \\
\text { and } \quad[\mathrm{X}] & =\frac{\left[\mathrm{X}^{\prime}\right]}{\mathrm{K}_{2}[\mathrm{~S}]}
\end{aligned}
$$

Substituting these in equation (11) and solving for [X'] one obtains,

$$
\left[X^{\prime}\right]=\frac{K_{1} K_{2} K_{3}[C A B]_{t}[P P A][R u(H)]\left[H^{+}\right]}{1+K_{1}\left[H^{+}\right]+K_{1} K_{2}\left[H^{+}\right][R u(H)]\left\{1+K_{3}[P P A]\right\}}
$$

By substituting for [X'] from equation (12) in equation (10), the following rate law (13) is obtained,

$$
\text { rate }=\frac{K_{1} K_{2} K_{3} k_{4}[C A B]_{t}[P P A][R u(H I)]\left[H^{+}\right]}{1+K_{1}\left[H^{+}\right]+K_{1} K_{2}\left[H^{+}\right][R u(H)]\left\{1+K_{3}[P P A]\right\}}
$$

rate $=k^{\prime}[C A B]$, rate law (13) can be transformed into equations (14) to (16).

$$
\begin{gathered}
\mathrm{k}^{\prime}=\frac{K_{1} K_{2} K_{3} k_{4}[P P A][R u(I I)]\left[H^{+}\right]}{1+K_{1}\left[H^{+}\right]+K_{1} K_{2}\left[H^{+}\right][R u(I I)]\left\{1+K_{3}[P P A]\right\}} \\
\frac{1}{k^{\prime}}=\frac{1}{K_{1} K_{2} K_{3} k_{4}[P P A][R u(I I I)]\left[H^{+}\right]}+\frac{1}{K_{2} K_{3} k_{4}[P P A][R u(I I I)]}+\frac{1}{K_{3} k_{4}[P P A]}+\frac{1}{k_{4}} \\
\frac{1}{k^{\prime}}=\frac{1}{K_{3} k_{4}[P P A]}\left\{\frac{1}{K_{1} K_{2}[R u(I I I)]\left[H^{+}\right]}+\frac{1}{K_{2}[R u(I I I)]}+1\right\}+\frac{1}{k_{4}}
\end{gathered}
$$

Based on equation (16), plot of $1 / \mathrm{k}^{\prime}$ versus $1 /[\mathrm{PPA}]$ (Fig. 4) at constant $[\mathrm{Ru}(\mathrm{III})],\left[\mathrm{H}^{+}\right]$and temperature has been found to be linear $(\mathrm{r}=0.988)$. The decomposition constant $\mathrm{k}_{4}$ was calculated $\left(\mathrm{k}_{4}=6.06 \times 10^{-3} \mathrm{~s}^{-1}\right)$ from the intercept of the plot.

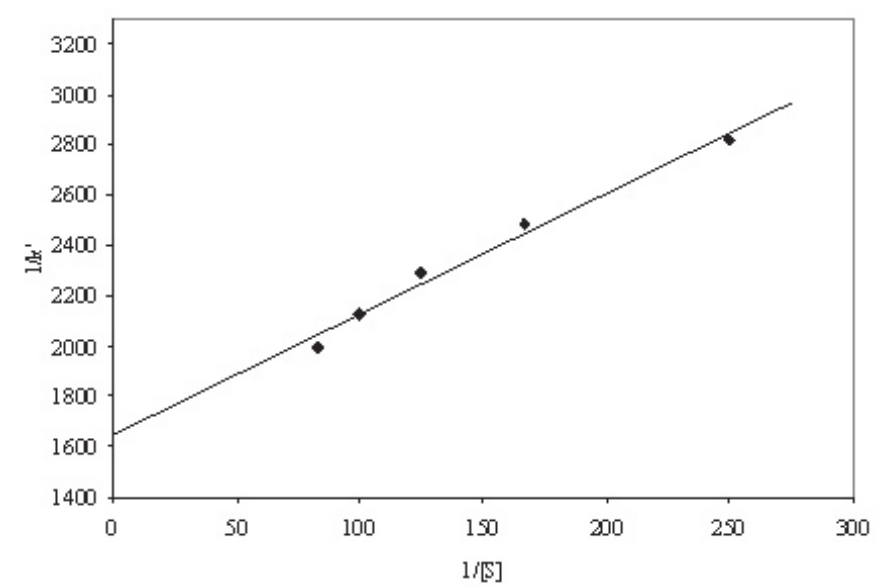

Fig. 4: Plot of 1/k' vs. 1/[PPA].

In Scheme 1, S represents substrate, $X$ and $X^{\prime}$ represent complex intermediate species whose structures are shown in Scheme 2, where a detailed mechanistic interpretation of $\mathrm{Ru}(\mathrm{III})$-catalyzed PPA oxidation by $\mathrm{CAB}$ in $\mathrm{HCl}$ medium is proposed. PPA with one mole of $\mathrm{CAB}$ get oxidized to benzaldehyde, acetaldehyde and Ammonia. The oxygen atom of the oxidant is coordinated to the metal center of the active catalyst species, $\left[\mathrm{RuCl}_{5}\left(\mathrm{H}_{2} \mathrm{O}\right]^{2-}\right.$ to form a loosely bound metal complex X. [step (i) of Scheme 2]. Then the $\mathrm{NH}_{2}$ group of the substrate readily reacts with the complex, $\mathrm{X}$ to give an another intermediate complex, $\mathrm{X}^{\prime}, \mathrm{RNH}_{2}$ and releasing $\left[\mathrm{RuCl}_{5}\left(\mathrm{H}_{2} \mathrm{O}\right)\right]^{2-}[\operatorname{step}(\mathrm{ii})$ of Scheme 2]. This intermediate $\mathrm{X}^{\prime}$ undergo intermolecular rearrangements [steps (iii) and (iv)] forming benzaldehyde and acetaldehyde.

A change in solvent composition by varying the $\mathrm{CH}_{3} \mathrm{CN}$ content in $\mathrm{CH}_{3} \mathrm{CN}$ $-\mathrm{H}_{2} \mathrm{O}$ affects the reaction rate. The general equation relating to the effect of dielectric constant to the reaction rate in a bimolecular reaction has been derived by Landskroner and Laidler ${ }^{32}$. For the limiting case of zero angle of approach between two dipoles, $\mathrm{Amis}^{33}$ has shown that,

$$
\ln k_{D}^{\prime}=\ln k_{D-\infty}^{\prime}-\frac{2 \mu_{1} \mu_{2}}{D k T^{3}}
$$

Where $\mathrm{K}^{\prime}$ is a function of dielectric constant $\mathrm{D}, \mu_{1}$ and $\mu_{2}$ are the dipole moments of reactions, $\mathrm{r}$ is the distance of approach for two dipoles, $\mathrm{k}$ is the Boltzmann constant and $\mathrm{T}$ is the absolute temperature. Equation (17) predicts a linear relation between log k' versus 1/D. The slope of the line should be negative for a reaction between two dipole molecules and positive for iondipole reactions. In the present case, the plot of log k' versus 1/D is linear with a positive slope, thus supporting the participation of ion-dipole species in the rate determining step.

The observed solvent isotope effect supports the proposed mechanism and 
the derived rate law. For a reaction involving a fast equilibrium $\mathrm{H}^{+}$or $\mathrm{OH}^{-}$ion transfer, the rate increases in $\mathrm{D}_{2} \mathrm{O}$ medium, since $\mathrm{D}_{3} \mathrm{O}^{+}$and $\mathrm{OD}^{-}$are stronger acid and stronger base respectively than $\mathrm{H}_{3} \mathrm{O}^{+}$and $\mathrm{OH}^{-}$ions ${ }^{34,35}$. In the present case, the observed solvent isotope effect of $k^{\prime}\left(\mathrm{H}_{2} \mathrm{O}\right) / k^{\prime}\left(\mathrm{D}_{2} \mathrm{O}\right)>1$ is due to the protonation step followed by hydrolysis involving the $\mathrm{OH}^{2}$ bond scission. The retardation of rate in $\mathrm{D}_{2} \mathrm{O}$ is due to the hydrolysis step which tends to make the normal kinetic isotope effect. The proton inventory studies made in $\mathrm{H}_{2} \mathrm{O}-\mathrm{D}_{2} \mathrm{O}$ mixture could throw lioht on the nature of the transition state. The dependence of the rate constant, $\mathrm{k}_{\mathrm{n}}$ on the deuterium atom fraction ' $\mathrm{n}$ ' in the solvent mixture is given by the following form of Gross-Butler equation ${ }^{36,37}$.

$$
\frac{k_{0}^{\prime}}{k_{n}^{\prime}}=\frac{\pi T S\left(1-n+n \phi_{i}\right)}{\pi R S\left(1-n+n \phi_{j}\right)}
$$

Where $\phi_{\mathrm{i}}$ and $\phi_{\mathrm{j}}$ are isotope fractionation factor for isotopically exchangeable hydrogen sites in the transition state (TS) and in the ground/ reactant state (RS), respectively. The Gross-Butler equation permits the evaluation of $\phi_{\mathrm{i}}$ when the value of $\phi_{\mathrm{j}}$ is known. However, the curvature of proton inventory plot could reflect the number of exchangeable proton in the reaction ${ }^{36}$. Plot of $\mathbf{k}^{\prime}$ versus $\mathrm{n}$ (Fig.4) is a curve in the present case, and this in comparison with the standard curves, indicate the involvement of a single proton or H-D exchange in the reaction sequence ${ }^{38}$. This proton exchange is indicative of the participation of hydrogen ion in the formation of transition state.

The mechanism is further supported by the value of energy of activation and other thermodynamic parameters. The fairly high positive values of Gibb's free energy of activation and enthalpy of activation indicate that, the transition state is highly solvated, while the negative entropy of activation suggests the formation of the compact activated complex with fewer degrees of freedom. The reduction product $\left(\mathrm{RNH}_{2}\right)$ did not influence the rate, showing that it is not involved in pre-equilibrium. Addition of $\mathrm{Cl}^{-}$ion has no effect on the rate indicating that no free chlorine is formed in the reaction. All these observations also confirm the proposed mechanism and derived rate law.

\section{CONCLUSIONS}

Oxidation of PPA with $\mathrm{CAB}$ in hydrochloric acid medium is sluggish, but the reaction is facile in presence of $\mathrm{RuCl}_{3}$ catalyst. The conjugate acid, $\mathrm{C}_{6} \mathrm{H}_{5} \mathrm{SO}_{2} \mathrm{NHCl}$ was found to be reactive oxidizing species. The stiochiometry of the reaction was found to be 1:1 and the oxidation products of PPA in $\mathrm{HCl}$ medium were identified as benzaldehyde and acetaldehyde. The observed results have been explained by plausible mechanisms, and related rate law has been deduced.

\section{ACKNOWLEDGEMENT}

The authors are thankful to University of Mysore, Mysore, for financial support.

\section{REFERENCES}

1. M. M. Campbell, G. Johnson. Chem. Rev. 78, 65 (1978).

2. K. K. Banerji, B. Jayaram, D. S. Mahadevappa. J. Sci. Ind. Res. 46, 65 (1987).

3. D.H. Bremner, Synthetic Reagents 6, 9 (1986).

4. D.S. Mahadevappa, M. Sayeed Ahmed, N.M. Madegowda. Int. J. Chem. Kinet. 15, 775 (1983).

5. K. N. Mohana, Rangaswamy, K. M. Lokanath Rai, Oxid. Commun. 28, 394, (2005).

6. S.K. Revathi, S. Ananda, Rangaswamy, K.N. Mohana, Collect Czech. Chem. Commun. 69, 1577, (2004).

7. C.R. Raju, K.N. Mohana, H.S. Yathirajan, K.S. Rangappa, Indian. J. Chem. 40A, 613 (2001).

8. B.N. Usha, Rangaswamy, H.S. Yathirajan, J. Indian Chem. Soc. 61, 812, (1984).

9. Sharon Alger, Karen Larson, Vicky Boyce, Helen Seagle, Anne-Marie Fontvieille, T. Robert, Ferraro, Russel Rising, Eric Ravussin, Am. J. Clin. Nutr. 57, 120, (1993).

10. H.S. Yathirajan, Rangaswamy, D.S. Mahadevappa, Collect. Czech. Chem. Commun. 47, 1826 (1982).

11. M.P. Raghavendra, K.S. Rangappa, K.M.L. Rai, J. Carbohydr. Chem. 16, 343, (1997).
12. Feigl F Spot Tests in Organic Analysis, Elsevier, Amsterdam, New York, 1975 , pp 244 and 245.

13. J.R.A. Pollock, R. Stevens Dictionary of organic compounds, Erye and Spottilwood Ltd., London, UK, 1965, p. 2820.

14. E. Bishop, V.J. Jennings, Talanta 1, 197, (1958).

15. J.C. Morris, J.R. Salazar, M.A. Winemann, J. Am. Chem. Soc. 70, 2036 (1948).

16. T. Higuchi, K. Ikeda, A. Hussain, J. Chem. Soc. (B) 546, (1967).

17. D.S. Mahadevappa, Rangaswamy, Rev. Roumaine de chimie 22, 1233, (1977).

18. Rangaswamy, D.S. Mahadevappa, Indian. J. Chem. 14A, 463, (1976).

19. F.F. Hardy, J.P. Johnston, J. Chem. Soc. Perkin Trans II 742, (1973).

20. S.S. Narayanan, V.R.S. Rao, Radio. Chim. Acta. 32, 221, (1983).

21. M. Subhashini, M. Subramaniyan, V.R.S. Rao, Talanta 32 1082, (1985).

22. H.H. Cady, R.E. Connick, J. Am. Chem. Soc. 80, 2646, (1958).

23. R.E. Connick, D.A. Fine, J. Am. Chem. Soc. 82, 4187, (1960).

24. T. Davfokratova, Analytical Chemistry of Ruthenium, Academy of Sciences, USSR, 1963, pp. 54, 71 and 97.

25. J.R. Backhours, F.D. Dwyer, N. Shales, Proc. Roy. Soc. 53, 146, (1950)

26. W.P. Griffith, The Chemistry of Rare Platinum metals, Interscience, New York, 1967, p. 4.

27. B. Singh, N.B. Singh, B.B.L. Saxena, J. Indian Chem. Soc. 61, 319, (1984).

28. B. Singh, D.K. Singh, D. Singh, J. Mol. Cat. 78, 207, (1988).

29. S. Ananda, B.M. Venkatesha, D.S. Mahadevappa, N.M.M. Gowda, Int. J. Chem. Kinet. 25, 755 (1993).

30. Puttaswamy, R. Ramachandrappa, Trans. Met. Chem. 24, 326, (1996).

31. Puttaswamy, R.V. Jagadeesh, Nirmala Vaz, Radhakrishna, J. Mol. Cat. A: Chamical, 229, 211 (2005).

32. D.A. Landskroner, K. J. Laidler, Trans Faraday Soc. 52, 200, (1956).

33. E S. Amis, Solvent Effects on Reaction Rates and Mechanisms, Academic Press, New York, 1966.

34. C.J. Collins, N.S. Bowman, Isotope Effects in Chemical Reactions, Van Nostrand Reinhold, New York, 1970 p.267.

35. K.B. Wiberg, Chem. Rev. 55, 713 (1955); K.B. Wiberg, Physiacl Organic Chemistry, Wiley, New York, 1964.

36. W.J. Albery, M.H. Davies, J. Chem. Soc. Faraday Trans. 68, 167 (1972).

37. G. Gopalakrishnan, J.L. Hogg, J. Org. Chem. 50, 1206 (1985).

38. N.S. Isaacs, Physical Organic Chemistry, Wiley, New York, 1987, p. 275 